\title{
Assessing the impact of the 2012 European Football Championships on the Polish economy
}

\author{
Jakub Borowski* \\ Department of Economics II, \\ Warsaw School of Economics, \\ Al. Niepodległości 162, 02-554 Warsaw, Poland \\ E-mail: jakub_borowski@poczta.onet.pl \\ *Corresponding author
}

\section{Jakub Boratyński}

Institute of Econometrics,

University of Lodz,

Rewolucji 1905r. 41, 91-214 Lodz, Poland

E-mail: jborat@uni.lodz.pl

\section{Adam Czerniak}

Department of Economics II,

Warsaw School of Economics,

Al. Niepodległości 162, 02-554 Warsaw, Poland

E-mail: adam.czerniak@gmail.com

\section{Paweł Dykas}

Faculty of Economics and Management Jagiellonian University, Gołębia 24, 31-007 Cracow, Poland

E-mail: paweldykas@op.pl

\section{Mariusz Plich}

Institute of Econometrics,

University of Lodz,

Rewolucji 1905r. 41, 91-214 Lodz, Poland

E-mail: plich@uni.lodz.pl

\section{Ryszard Rapacki}

Department of Economics II,

Warsaw School of Economics,

Al. Niepodległości 162, 02-554 Warsaw, Poland

E-mail: rrapacki@sgh.waw.pl 


\title{
Tomasz Tokarski
}

Faculty of Economics and Management

Jagiellonian University,

Gołębia 24, 31-007 Cracow, Poland

E-mail: tomtok67@tlen.pl

\begin{abstract}
In this paper, we examine the impact of the UEFA EURO 2012 the Polish economy. The simulations are based on a dynamic computable general equilibrium (CGE) model and cover the years 2008-2020. We find that the main source of economic benefits is the acceleration of investments in transport infrastructure, which fosters growth of total factor productivity and the inflow of foreign direct investment. This contrasts with the results for more developed countries hosting major sporting events, where infrastructure effects are reported to be of less importance. Overall cumulative real GDP gains amount to $2.1 \%$ of the 2009 GDP level under the basic scenario.
\end{abstract}

Keywords: major sporting events; impact studies; 2012 European Football Championship; UEFA EURO 2012; Barcelona effect; infrastructure investment; computable general equilibrium model; CGE modelling; Poland; Polish economy.

Reference to this paper should be made as follows: Borowski, J., Boratyński, J., Czerniak, A., Dykas, P., Plich, M., Rapacki, R. and Tokarski, T. (2013) 'Assessing the impact of the 2012 European Football Championships on the Polish economy', Int. J. Sport Management and Marketing, Vol. 13, Nos. 1/2, pp.74-103.

Biographical notes: Jakub Borowski is an Assistant Professor at the Chair of Economics II in Warsaw School of Economics (WSE). He graduated from the Faculty of Banking and Finance in WSE. He received DAAD scholarship at Humboldt University in Berlin and conducted research in the National Bank of Austria, ifo Institute in Munich, German Institute for Economic Research and German Ministry of Finance. The main areas of his research interests are monetary integration and macroeconomic policy in the small open economy.

Jakub Boratyński is an Assistant Professor at the Chair of Theory and Analyses of Economic Systems, University of Lodz, Poland. He specialises in the development and use of multi-sector economic models.

Adam Czerniak is a $\mathrm{PhD}$ candidate and a Teaching Assistant at the Department of Economics II, Warsaw School of Economics (WSE). He graduated from the Faculty of Economics in WSE with specialisation in mathematical economics and forecasting. He was a Research Assistant at the World Bank, Economist at the FOR Foundation and since February 2008, he has been an Economist at Invest-Bank in Warsaw. He is also a Fellow of the Ronald Coase Institute. He is an author and co-author of papers on economic sociology, institutional analysis, forecasting and economics of information.

Pawel Dykas is a PhD candidate and Teaching Assistant at the Faculty of Economics, Jagiellonian University in Cracow. He graduated from the Faculty of Mathematics and the Faculty of Economics, Jagiellonian University. His main interests include mathematical theory of economic growth, analysis of the spatial diversity of economic development and the analysis of regional differences in labour market. He is an author and co-author of publications on economic growth, regional development and labour market. 
Mariusz Plich is a Professor at the University of Lodz and the Director of the Institute of Econometrics. He specialises in the development and use of multi-sector economic models. His main research areas are links between the environment and the economy, social security systems, consumption, and changes in economic structures.

Ryszard Rapacki is a Full Professor and Head of the Department of Economics, Warsaw School of Economics. He is also an Adjunct Professor at Carlson School of Management, University of Minnesota, Senior Fellow at the Centre for European Integration Studies (ZEI), University of Bonn and a Professor and Coordinator at the National School of Public Administration, Warsaw. His main research areas are macroeconomic theory, economic policy, systemic transformation in East-Central Europe, privatisation, economic growth and real convergence. He is the author of some 200 articles, books, textbooks and conference papers, published in Poland, Austria, Belgium, Germany, Mexico, Taiwan, the UK and the USA.

Tomasz Tokarski is a Professor of Economics at the Institute of Economics and Management, Jagiellonian University, Cracow, Poland. He is the author of many papers and eight books concerning economic growth theory and regional development in Poland.

\section{Introduction}

\subsection{The problem}

Poland and Ukraine will jointly organise the European Championships in football (soccer) to be held in 2012. The decision to grant the two countries the right to host one of the biggest sporting events in the world was announced by the Union of European Football Associations (UEFA) in April 2007. The decision aroused great expectations in Poland ${ }^{1}$, as it is widely believed that major sporting events may bring many benefits to host countries. One believed benefit is a lasting increase in inbound tourism revenues, both during the event and afterwards, as a consequence of an improved image of the country that helps to attract more foreign tourists. Another example of the benefits in question is the development of sport, hotel, leisure and cultural infrastructure which in the long run may facilitate organisation of other big international events. In the case of catching up economies like Poland, however, the greatest gains are believed to result from the rise of country's economic potential due to the extension and upgrading of the existing transport infrastructure (roads, railways, airports, and urban transport), whose density and quality are, as a rule, well below the standards prevailing in developed countries. The enhanced economic potential contributes in turn to accelerating economic development of the host country.

The foregoing expected results of big sporting events indicate that the organisation of the European Football Championships (EFC) (referred to as EURO 2012) may be interpreted as a positive external shock that is likely to exert a sizeable impact on the Polish economy. The latter is envisioned to occur both in the short run, i.e., during the preparatory stage of the tournament and its course, and in the long run, extending for many years following the event. The aim of this paper is to assess the economic effects of 
the EURO 2012 in the years 2008-2020, based on simulations conducted by means of a computable general equilibrium (CGE) model of the Polish economy.

\subsection{Literature review}

\subsubsection{Possible research approaches}

The economic effects stemming from the organisation of international sporting events are a subject of numerous empirical studies. They may be divided into two broad groups. The first and less numerous group is based on investment project appraisal approach - the studies involved aim at estimating the direct costs and revenues of organising an event, expressed in terms of the net present value of the project (Shaffer et al., 2003). However, this kind of approach faces many limitations, such as the difficulty of estimating all relevant costs and benefits related to the organisation of the event as well as determining its opportunity cost. The latter limitation boils down to the need to indicate the investment project being a viable option to international sporting events and to find the appropriate rate of return on this investment (Kasimati, 2003) to be used for discounting the future cash flows. This difficulty is of particular significance in the case of organising the EURO 2012, which can be perceived primarily as a factor being used to implement badly needed infrastructure investments.

The second group of empirical studies focuses on assessing the impact of international sporting events on the economy, expressed in terms of the response of basic macroeconomic variables (GDP and its main components, employment, personal incomes, prices) to this kind of external shock. The studies involved usually compare the macroeconomic effects of an event to a hypothetical scenario of not organising this particular event. The key underlying justification for such an approach is that the organisation of major sporting events leads to higher revenues from inbound tourism and puts strong pressure on the implementation of investment projects that - under 'no-event' scenario - probably would not have been undertaken at all. Yet, still another approach to this problem is feasible, assuming that such investments would be undertaken anyway, even with no stimulus coming from the sporting event - but later. Seen from this perspective, the investment outlays related to the organisation of an international sporting event can be analysed in terms of optimal timing of investment (Brealey and Myers, 2000). This paper fits into this category of empirical research.

\subsubsection{Impact areas}

One of the most frequently discussed effects of the organisation of international sporting events is a short-term rise in demand triggered by the inflow of tourists, athletes and guests participating in the event (Rütter et al., 2004; Ribeiro et al., 2004). The increase in inbound tourism revenues recorded during the sports events usually does not have sizeable influence on aggregate demand (Martins et al., 2004; Helmenstein and Kleissner, 2008; Rütter et al., 2004).

The second and potentially more powerful outcome, called the 'legacy effect', is associated with an improvement in tourist attractiveness of the country, which in turn contributes to a lasting increase in the inflow of tourists and their expenditures in the longer run (Brunet, 2005; Rütter et al., 2004; Madden, 2002; Ahlert, 2005; Bohlmann and van Heerden, 2008; Martins et al., 2004; Helmenstein and Kleissner, 2008). 
Still another economic effect of the organisation of major sporting events is a derivative of increased investment outlays on sports and tourism as well as on transport infrastructure (PricewaterhouseCoopers, 2004). These investments tend to positively stimulate demand in the short-term perspective (Martins et al., 2004; Ahlert, 2005) while in the long run they may also induce positive supply response (legacy effects), due to rising specialisation in production and stronger competition (Bougheas et al., 1999; Button, 1996; Chatterjee et al., 2003; Borensztein et al., 1998; Bohlmann and van Heerden, 2008). It should be mentioned, however, that the supply effects are attributed mainly to the transport infrastructure, whereas in the case of sport infrastructure they are sometimes questioned in ex-post analyses (Matheson and Baade, 2004; Kim et al., 2006).

The upgrading of transport infrastructure reduces the barriers to foreign trade, fosters growth of total factor productivity (TFP) and makes the return on capital go up, which creates incentives that increase inflow of foreign direct investments (FDI). The latter may in turn boost the growth of exports and employment, dissemination of modern management techniques, and transfer of new technologies and knowledge, thus improving competitiveness of the national economy (Choe, 2003; Démurger, 2001; Markusen and Venables, 1997; Bellak et al., 2009; Brunet, 2005).

\subsubsection{Research methods}

Empirical assessments of macroeconomic effects stemming from the organisation of mega sporting events tend to be conducted mainly by means of multi-sectoral models, usually of the input-output or CGE type (Kasimati and Dawson, 2009). ${ }^{2}$ This is mainly due to the multi-sectoral approach (disaggregation) offered by the two types of modelling. The disaggregation of the economy makes such models compatible with the typical level of detail embedded in the assumptions (scenarios) that describe the economic aspects of organising the event. Another important advantage of disaggregation consists in broader possibilities of confronting the relevant scenarios with various expert opinions (e.g., evaluation of the anticipated investment profitability).

The input-output approach - albeit allowing for the complexity of inter-sectoral economic interrelationships - is nevertheless burdened with a number of limitations. They result from the implicit presumption that the supply (and employment) of each sector may grow indefinitely - in line with the rising demand - at constant prices. Such a method does not take into account the constraints inherent to economic resources such as capital equipment. Most importantly perhaps within the context of the present study, the input-output approach does not support the analysis of effects stemming from the expansion of economic potential, as it is focused on describing the transmission of demand shocks between particular sectors of the economy.

Multi-sectoral economic models, integrating the input-output approach with econometric methods (Almon, 1991), constitute a major alternative to the CGE models. An example of using such a tool for assessing the impact of a large sporting event is the study of economic effects of the 2006 Football World Cup in Germany (Ahlert, 2005). The main difficulty inherent to that approach boils down to the requirement of relying on a very comprehensive and coherent database comprised of time series of industry variables. At the same time, the use of time series data makes it possible to validate the model in an ex-post simulation. However, the possibility of making use of the rational expectations concept, embedded in the CGE framework, is an advantage from the 
perspective of a study of easily predictable future economic shocks (such as those related to the planning of EURO 2012). It enables examining the results of inter-temporal optimisation of investment decisions. The CGE model's logic is also perhaps more perceptible in that it may be quite easily expressed by means of basic terms and assumptions used in microeconomics, whereas the integrated models of the type referred to above are built on more eclectic foundations. Bearing in mind all the above factors, we have decided to use the CGE model as the main research tool in this publication.

The remainder of the text is organised as follows.

In Section 2 we outline the main impact channels of the organisation of the EURO 2012 on the Polish economy and emphasise the differences between Poland and the other organisers of big sporting events. Section 3 explains the structure of the model whereas Section 4 reports the assumptions of the simulation. In turn, Section 5 presents major findings of our study, i.e., the macroeconomic effects of the EURO 2012 between 2008 and 2020 while Section 6 provides main conclusions.

\section{Direct and indirect macroeconomic effects of the EURO 2012 organisation}

The macroeconomic effects of the EURO 2012 in Poland assessed in this paper include the following:

Direct effects, i.e., the increase in the investment outlays during the preparatory stage and in consumption during the event itself.

- Short-term rise in inbound tourism revenues stemming from the inflow of football fans and guests during the EURO 2012.

- Increase in investments in sports, tourist and transport infrastructure.

- Short-term hike in demand fuelled by additional expenditures financed from the operational budget of the UEFA. The latter usually covers the costs connected with the rental of stadiums, security, marketing and other organisational tasks.

Indirect effects, lasting after the event.

- the country's higher tourist attractiveness and the resultant long-term increase in the number of incoming tourists and their expenditures ('Barcelona effect')

- increase in the country's economic productivity (potential output) resulting from a quantitative and qualitative improvement in the infrastructure (particularly in transport infrastructure)

- expansion of private investment, resulting from higher productivity and higher expected return on capital

- enhanced investment attractiveness of the country leading to an augmented FDI inflow and additional productivity growth.

The schematic picture of the above effects on the Polish economy due to the EURO 2012 is shown in Figure 1. It can be inferred from the figure that some of the indirect effects 
appear even before the event itself (e.g., augmented productivity as a derivative of investments in infrastructure), although their impact is then weaker.

The distinguishing features of this study, compared to the majority of empirical research of this kind published so far, are as follows:

1 The assessment of macroeconomic effects triggered by the EURO 2012 is based on the assumption that its organisation will bring about acceleration (i.e., earlier completion) of necessary investments in sports and transport infrastructure which otherwise, in the absence of this external shock, would have been undertaken later.

2 The analysis encompasses not only the demand-side effects of investments in transport infrastructure but also their positive impact on the supply-side represented here by TFP. One can see major benefits related to the EURO 2012 in this effect.

3 The study takes into account positive implications of an upgraded transport infrastructure for the inflow of FDI to Poland.

4 The simulation of economic effects of the EURO 2012 is performed by means of a dynamic (inter-temporal) CGE model which allows the assessment of the impact of organising the tournament on selected macroeconomic variables (aggregates) in consecutive years.

Figure 1 Economic effects of the EFC 2012 organisation

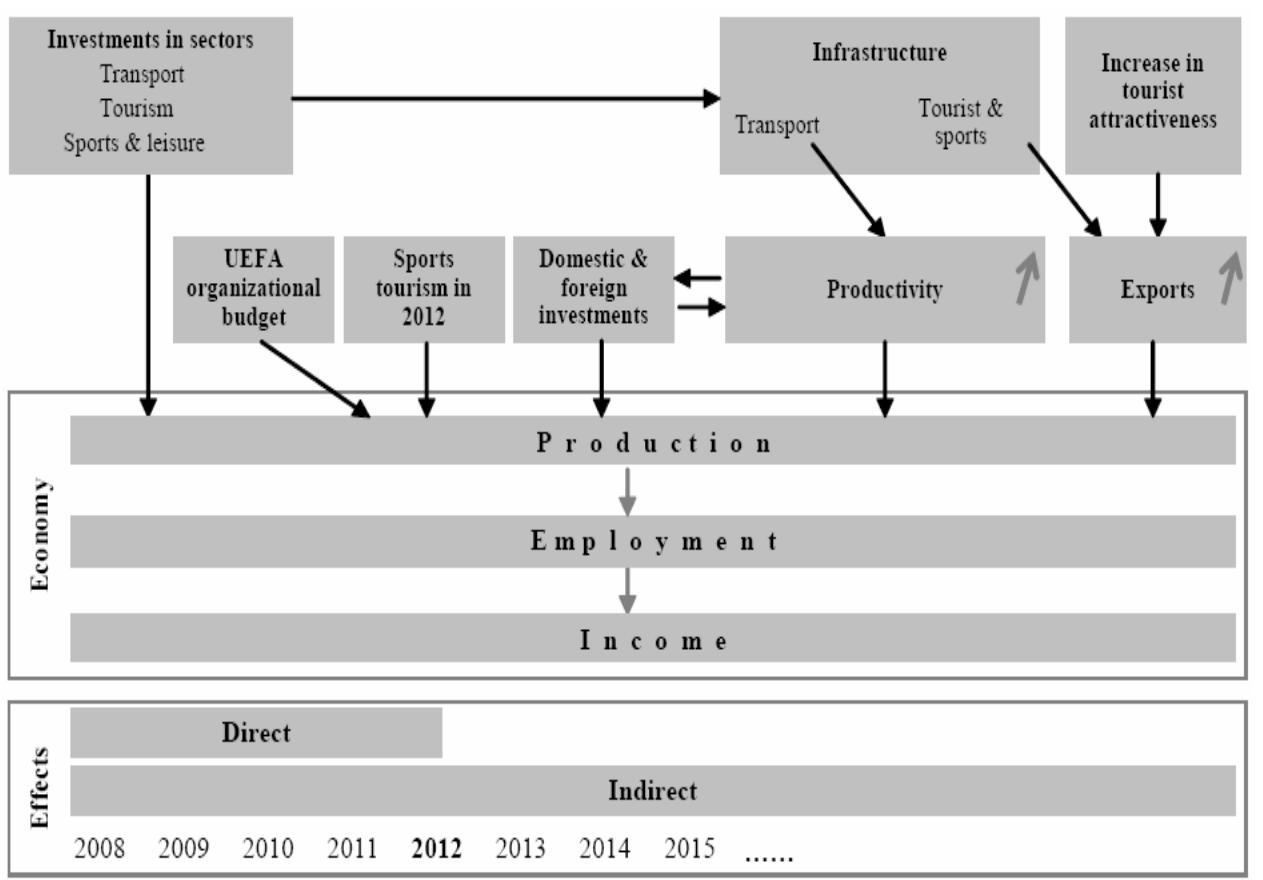

Source: Authors' design 


\section{Structure of the model}

The tool we have developed with a view to estimate the economic impact of the EURO 2012 is a dynamic CGE model. Its structure is largely based on specifications presented by Dixon and Parmenter (1996) and Horridge (2003). The model is dynamic, which means that:

- it features solutions for the consecutive calendar years (the simulations cover the 2008-2020 period)

- $\quad$ it describes the capital accumulation process - separately for each industry

- investment in each industry is determined by the anticipated future capital income and investment costs; model-consistent (rational) expectations were employed, meaning that the expectations formed in a given period about future values of different variables are consistent with the actual model outcomes for the future periods.

The model singles out 41 industries (according to $\mathrm{NACE}^{3}$ ) and the same number of commodity groups (according to CPA - classification of products by activity). It also features two additional, dummy industries (not included in the standard classifications) allowing to capture the activities related directly to the management of the EURO 2012 (UEFA operational budget), as well as the tournament-generated inbound tourism demand.

The production process in individual industries is described by nested production functions. Intermediate inputs, together with a primary factor bundle, are combined in fixed proportions, according to Leontief production function. The primary factor bundle is a constant elasticity of substitution (CES) combination of capital and labour, while intermediate inputs are CES composites of domestic and imported products. Industries are treated as multi-product ones - they can adjust the product-structure of their output according to constant elasticity of transformation (CET) production frontier. Each type of activity is characterised by a different production technology. Fixed capital is supposed to be industry-specific, while labour is homogenous and mobile between industries. The choice of capital and labour proportions, similar to sourcing of intermediate inputs, is based on cost minimisation principles. The same sourcing decisions (i.e., the choice between domestic and imported commodities) also relate to final demand, including consumption and investment.

On the demand side, household consumption is modelled using a perhaps adequate demand system [(PADS) - developed by Almon (1996)] - demand system for a single representative household and 12 categories of consumption commodities (according to $\mathrm{COICOP}^{4}$ ), with econometrically estimated parameters. Aggregate consumption is proportional to current income. Exports are assumed to be adjusting in response to the domestic capacity changes. Investment demand by industries, determined at a level maximising their net present value (in the finite and discrete time framework), is transformed into six expenditure types (corporate and general government investments; each of these categories split into: outlays for buildings and structures, machinery and equipment, and transportation equipment). Some investment types, including those related to EURO 2012, are exogenous. Other exogenous categories include government 
consumption and change in inventories. Income distribution is modelled in the national accounts framework, for six institutional sectors (Boratyński, 2009).

The most important relationships included in the model are briefly characterised below. The presentation of equations is stylised at some points, in order to abstract from unnecessary details (including functional forms in most cases). Subscript $t$ denotes time, while $i$ and $j$ denote industries or commodities (depending on the context). Character $f$ is used as a generic function symbol, so it represents any particular function. The $(+)$ and (-) signs denote a positive and a negative relationship, respectively.

As an essential CGE feature, the model reflects various substitution effects. The equations below represent capital and labour substitution:

$$
\begin{gathered}
K_{i t}=Y_{i t} \cdot f\left(P_{i t}^{(K)} / P_{t}^{(L)}\right) \\
(-) \\
L_{i t}=Y_{i t} \cdot f\left(P_{i t}^{(K)} / P_{t}^{(L)}\right)
\end{gathered}
$$

where $Y$ is primary factor bundle, $K$ - capital input (stock), $L$ - labour input, $P^{(K)}$ - capital rental rate, $P^{(L)}$ - wage rate (uniform across industries). Equations (1) and (2) are derived from cost-minimising principle under CES technology. According to the following equation:

$$
Y_{i t}=X_{i t} / T F P_{i t}
$$

demand for primary factor composite is proportional to industry's output, $X$, and inversely proportional to total factor productivity, TFP. Material (intermediate) inputs are proportional to output (i.e., Leontief technology characterises the use of intermediate inputs $Z$ ):

$$
Z_{i j t}=A_{i j} \cdot X_{j t}
$$

where $A_{i j}$ is the amount of product $i$ required as intermediate input per unit of output of industry $j$. Equation (4) actually implies that changes in demand for a single industry's products also affect the activity in the cooperating industries. Intermediate inputs are composites of domestic and imported goods, proportions of which change due to changes in relative prices (the Armington specification was used):

$$
\begin{gathered}
Z_{i j t}^{(D)}=Z_{i j t} \cdot f\left(P_{i t}^{(D)} / P_{i t}^{(M)}\right) \\
(-) \\
Z_{i j t}^{(M)}=Z_{i j t} \cdot f\left(P_{i t}^{(D)} / P_{i t}^{(M)}\right)
\end{gathered}
$$

$(+)$

Therefore, demand for domestically produced intermediate input $\left(Z^{(D)}\right)$ is proportional to composite demand, it is also negatively related to the ratio of domestic and imported commodity prices $\left(P^{(D)}\right.$ and $P^{(M)}$, respectively). $P^{(M)}$ represents prices in the domestic currency, so it is a product of foreign-currency prices of imports, $P F^{(M)}$, and the exchange 
rate, $H\left(P_{i t}^{(M)}=P F_{i t}^{(M)} \cdot H_{t}\right)$. The same domestic/imported substitution mechanism also concerns final demand sourcing decisions (we skip the corresponding equations here).

Price determination is based on a perfect-competitive model, i.e., zero pure profit condition is applied, and therefore price equals the sum of unit costs of production:

$$
P_{j t}^{(D)}=\left(\sum_{i} Z_{i j t} \cdot P_{i t}^{Z}+K_{j t} \cdot P_{j t}^{(K)}+L_{j t} \cdot P_{t}^{(L)}\right) / X_{j t}
$$

Prices are also an instrument that facilitates equilibrium in commodity markets. Equilibrium conditions simply state that demand for a given commodity equals supply. These conditions (actually formulated separately for domestic and imported commodities) imply that:

$$
\begin{aligned}
& X_{i t} \cdot P_{i t}^{(D)}+M_{i t} \cdot P_{i t}^{(M)}+T A X_{i t} \\
& =\sum_{i} Z_{i j t} \cdot P_{i t}^{(Z)}+C_{i t} \cdot P_{i t}^{(C)}+G_{i t} \cdot P_{i t}^{(G)}+I_{i t} \cdot P_{i t}^{(I)}+V_{i t} \cdot P_{i t}^{(V)}+E_{i t} \cdot P_{i t}^{(E)}
\end{aligned}
$$

where $M_{i}$ denotes imports of commodity $i, T A X_{i}$ - sum of indirect taxes on commodity $i$, $C_{i}$ - household consumption of commodity $i$, and $G, I, V, E$ - government consumption, investment, change in inventories and exports, respectively; $P$ with corresponding superscripts denote purchasers' prices of commodities (these prices are derived in the model from basic prices of domestic production and imports, $P^{(D)}$ and $P^{(M)}$, as their weighted averages, augmented by taxes and margins). For simplicity, we omit presentation of how margins are handled. We also abstract from a multi-commodity production structure, that is actually present in the model.

On the final demand side, household consumption of individual commodities is modelled as:

$$
C_{k t}=f\left(C_{t}, \Delta C_{t}, P_{k t}^{(C)} / C P I_{t}, P_{k t}^{(C)} / P_{1 t}^{(C)}, P_{k t}^{(C)} / P_{2 t}^{(C)}, \ldots, P_{k t}^{(C)} / P_{N t}^{(C)}\right)
$$

where $C_{k}$ represents household demand for $k^{\text {th }}$ consumption commodity (out of $N$ commodities, by COICOP), $C$ - aggregate consumption, $P^{(C)}$ - prices of consumption commodities, $C P I$ - aggregate consumer price index. In this case the necessary parameters were estimated using time-series data. Consumption by COICOP is transformed into consumption by CPA using an appropriate bridge matrix.

In the simulation of EURO 2012 scenarios, aggregate consumption in a given period is a fixed proportion, $C S$, of household disposable income, $I N C$, i.e.:

$$
C_{t} \cdot C P I_{t}=C S_{t} \cdot I N C_{t}
$$

Government consumption, $G$, is exogenous in the model, as is the change in inventories. Foreign demand, $E$, is inversely related to the ratio of domestic to world prices:

$$
E_{i t}=W_{t} \cdot f\left(P_{i t}^{(E)} /\left(P W_{i t} \cdot H_{t}\right)\right)
$$

$(-)$

The term $W$ represents possible shifts in foreign demand that are not related to price changes. With respect to foreign trade, we use two alternative closures in our simulations. 
We assume that productivity induced capacity changes of the domestic economy are absorbed by foreign demand without the requirement of offering noticeably lower prices (the output expansion being not only of the quantitative nature in this case). This assumption is consistent with the fact that in recent years the Polish economy recorded a sizeable growth and export expansion, while the terms of trade did not deteriorate. Technically such a closure is facilitated by fixing the real exchange rate and endogenising the $W$ terms in equation (11). We take a different approach to modelling the effects of increased tourist demand (which was performed in a separate simulation). In this case it is likely that additional expenditure of foreign tourists would tend to cause real appreciation of the domestic currency, which stimulates imports and causes some export contraction. Under this closure, the position of the foreign demand curve is fixed ( $W$ terms are exogenised), while the real exchange rate is allowed to adjust.

The remaining element of final demand is investment - which is discussed further.

The model also mimics the formation of household income, as well as general government revenues. The starting points in determining household income are labour and capital income, which are further modified by various redistribution transfers, being mostly endogenous (e.g., PIT payment or social benefits). Similarly, corporations' incomes are linked to capital income 'collected' in industries. Tax revenues of general government, TAXES, are modelled as follows:

$$
\begin{aligned}
& T A X E S=\sum_{i} \sum_{j} Z_{i j t} \cdot P_{i t}^{(Z)} \cdot \frac{T_{i j}^{(Z)}}{\left(1+T_{i j}^{(Z)}\right)} \\
& +\sum_{i}\left(\begin{array}{c}
C_{i t} \cdot P_{i t}^{(C)} \cdot \frac{T_{i}^{(C)}}{\left(1+T_{i}^{(C)}\right)}+G_{i t} \cdot P_{i t}^{(G)} \cdot \frac{T_{i}^{(G)}}{\left(1+T_{i}^{(G)}\right)} \\
+I_{i t} \cdot P_{i t}^{(I)} \cdot \frac{T_{i}^{(I)}}{\left(1+T_{i}^{(I)}\right)}+E_{i t} \cdot P_{i t}^{(E)} \cdot \frac{T_{i}^{(E)}}{\left(1+T_{i}^{(E)}\right)}
\end{array}\right) \\
& +T^{(P I T)} \cdot I N C G_{t}+T^{(C I T)} \cdot \text { CINCG }_{t}+\text { OTHTAX }_{i}
\end{aligned}
$$

where $T_{i j}^{(\mathrm{Z})}, T_{i}^{(\ldots)}, T^{(P I T)}, T^{(C I T)}$ are effective (ad valorem) rates of: indirect taxes on intermediate demand, indirect taxes on final demand components, personal income tax, and corporate income tax, respectively; INCG is pre-tax household income, while CINCG is a proxy for pre-tax corporate income; OTHTAX stands for other minor tax categories. Note that indirect tax rates vary across commodities and uses, which makes the framework for modelling indirect tax revenues significantly detailed.

The dynamic features of the model include capital accumulation, investment behaviour and public debt accumulation. In general, investment in a given industry, INV, is a sum of three components, namely private domestic investment, $I P R$, public investment, $I P U$, and foreign direct investment, $I F$ :

$$
I N V_{j t}=I P R_{j t}+I P U_{j t}+I F_{j t}
$$

Public and foreign investment are exogenous and thus subject to scenario assumptions, while private domestic investment is determined in the model, such that it maximises the net present value of an industry. Model-consistent expectations are employed, meaning that the expectations formulated in period $t$, concerning capital rentals and investment 
costs in period $t+n$, equal actual model solution for period $t+n$. Formally investment equations are a solution to the problem of maximising (see Dixon and Parmenter, 1996):

$$
\sum_{t=0}^{T-1}\left\{\frac{P_{j, t+1}^{(K)} \cdot K_{j, t}}{(1+R)^{t}}-\frac{P_{j, t+1}^{(I)} \cdot\left(I P R_{j, t+1}+A D J_{j, t+1}\right)}{(1+R)^{t}}\right\}+T V_{j T} \cdot K_{j T}
$$

by choosing appropriate $I P R_{j, t+1}$ values, subject to the constraint representing the capital accumulation formula:

$$
K_{j t}=K_{j, t-1} \cdot\left(1-D E P_{j}\right)+I N V_{j, t-1}
$$

where $D E P$ is a capital depreciation rate. In equation (14), $R$ is interest rate, $A D J$ represents investment cost-of-adjustment terms which prevents unrealistically large responses to the rate of return changes; $T V$ is a terminal value of a unit of capital at the end $(T)$ of the industry's planning period (see Dixon and Parmenter, 1996, for details concerning the two latter items). $T V$ is calibrated in such a way that it assures assumed steady state growth rate of capital at the end of the planning period. Equation (15) implies that capital is industry-specific, so it cannot flow between industries. It must be noted that a part of public investment, namely that referring to road investment, is excluded from investment in equation (15), so there is no increase in capital stock related to roads. Instead, these investments are assumed to impact on total factor productivity, as explained in the following section. Note that $I N V_{j}$ are investments by industries - they are translated into demand for specific investment goods, $I_{i}$, with the use of an appropriate bridge matrix.

As a third inter-temporal mechanism, the model calculates changes to public debt, by cumulating annual deficits of general government. In these calculations the debt service costs are taken into account, based on an average interest rate on debt. Finally, macroeconomic variables such as GDP, are determined as aggregates of industry/commodity-level variables. The model therefore employs a bottom-up approach.

The model was implemented in general equilibrium modelling package (GEMPACK; Harrison and Pearson, 1996). The deployed technique involved simultaneous solution for all the examined periods (Malakellis, 2000). The model's intra-temporal equations were calibrated to an estimated supply and use table for 2007, and national accounts data by institutional sectors for that year. The baseline (benchmark) solution was generated under assumptions concerning the rate of technical change, inflation, labour supply, etc. These assumptions were consistent with the economic trends in Poland over the previous years.

\section{Assumptions and scenarios}

\subsection{Basic assumptions}

The factors affecting the Polish economy, associated with the organisation of the EURO 2012, taken into account in our simulations include:

- $\quad$ higher inbound tourism revenues

- $\quad$ acceleration of infrastructure investments (transport, sports and team base camps) ${ }^{5}$ 
- the increased TFP level resulting from the upgrading of transport infrastructure

- the earlier inflow of FDI, induced by improved transport infrastructure

- direct expenditures from the UEFA operational budget.

The effects of organising the UEFA EURO 2012 different scenarios: basic, optimistic and pessimistic. Such an approach reflects uncertainty about the economic effects of the tournament. It is worth mentioning that each simulation scenario is either consistently pessimistic, or consistently optimistic or consistently intermediate (the basic scenario). In other words, the optimistic scenario is based on optimistic assumptions regarding all the analysed economic impulses linked with the planning of the EURO 2012. No 'mixed' scenarios, with built-in both pessimistic and optimistic or intermediate assumptions, are considered. In practical terms, however, simulation results for the 'mixed' scenarios should lie between the effects marked out for the consistently pessimistic scenario and the consistently optimistic one. Hence, the analysis embraces the whole spectrum of possible outcomes in accordance with the adopted assumptions.

It should be noted that - seen from the perspective of the whole period examined - the net change in the level of infrastructure investment equals zero. This result is consistent with the assumption that the investments in question would have been carried out regardless of the EURO 2012, but at a later date. Similarly, TFP rises only temporarily compared to the path projected in the benchmark scenario. Only the shock produced by the increase in the number of foreign tourists exhibits - within the time horizon considered - a permanent nature.

In this study, the term 'benchmark scenario' refers to a simulation variant representing a hypothetical development path of the Polish economy between 2008 and 2020 provided the EURO 2012 was not held in Poland. This scenario makes an implicit assumption that the transport infrastructure investments would be undertaken, and stadium and team base camps built anyway, although with a significant time-lag compared to the case of the planning of the tournament. In order to assess the full economic effects of the event we compare the benchmark scenario with three other alternatives - i.e., the basic, optimistic and pessimistic scenarios. They shall be subsequently called 'EURO 2012 scenarios'. Each of the three scenarios reflects a varying composition of shocks associated with preparations and organisation of the event. They differ with respect to time distribution of inbound tourism revenues, the level of investment outlays, and FDI inflow. They are discussed in greater detail later in this section.

\subsection{Inbound tourism expenditure}

The tourism scenario is based on our projections of additional inbound tourism revenues between 2012 and 2020. As stated earlier, we divided the period covered by our analysis into two sub-periods - corresponding to the time distribution of the direct effects (year 2012) and indirect effects (2013-2020) of the EURO 2012 respectively. Our forecasts of additional inbound tourism revenues due to the extra inflow of foreign tourist during the three weeks of the tournament in June 2012 were based on pertinent assumptions on stadium capacity utilisation, ticket distributions, length of stay and expenditures of foreign fans as well as macroeconomic variables (exchange rates, 
inflation, and global economic growth). These assumptions were based on econometric estimations, expert consultations and the relevant experience of former hosts of the EFC, especially Austria, Switzerland and Portugal.

The indirect effects of the EURO 2012 for inbound tourism revenues in Poland will be mainly due to the so-called 'Barcelona effect' ${ }^{6}$, i.e., the increase in foreign tourist arrivals brought about by the improvement in the perceived attractiveness of mass-event-host. It has been assumed that the successful organisation of the tournament, improved transport infrastructure, and new accommodation facilities will translate into the growth of Poland's tourist attractiveness, measured by the $\mathrm{NBI}^{\mathrm{SM}}$ tourism index ${ }^{7}$. Under the basic scenario, the latter will rise to the highest level among the countries of the CEE region (up from 59.1 in 2008 to 59.9 in 2012), while under the pessimistic scenario it will match the level of the Czech Republic (up to 59.2) and under the optimistic scenario it will improve to 60.1 . In the next step we have estimated random-effects panel regressions for 37 countries in the years 2003-2007 with a view to capture the impact of an increase in the perceived tourist attractiveness of a country on the arrivals of foreign tourists coming for leisure purposes. The parameters of the best-fitted panel model suggest that a one point increase in the $\mathrm{NBI}^{\mathrm{SM}}$ tourism index of a given country contributes to an additional inflow of 611 thousand foreign tourists in this category annually.

A detailed breakdown of projected additional inbound tourism revenues from 2012-2020 corresponding to particular scenarios is presented in Table 1.

Table 1 Additional inbound tourism revenues in 2012-2020

\begin{tabular}{lccc}
\hline \multirow{2}{*}{ Year } & \multicolumn{3}{c}{ Scenario } \\
\cline { 2 - 4 } & Basic & Pessimistic & Optimistic \\
\hline 2012 & 768.3 & 576.2 & 768.3 \\
2013 & 499.2 & 62.4 & 624.0 \\
2014 & 501.2 & 62.7 & 626.5 \\
2015 & 503.7 & 63.0 & 629.6 \\
2016 & 514.9 & 64.4 & 643.7 \\
2017 & 526.5 & 65.8 & 658.1 \\
2018 & 538.4 & 67.3 & 672.9 \\
2019 & 551.0 & 68.9 & 688.7 \\
2020 & 564.3 & 70.5 & 705.3 \\
Total & $4,967.4$ & $1,101.1$ & $6,017.1$ \\
$\%$ of basic scenario & $100.0 \%$ & $22.2 \%$ & $121.1 \%$ \\
\hline
\end{tabular}

Note: PLN million, 2008 constant prices.

Source: Authors' calculations

In the basic scenario, the total inbound tourism revenues should rise, thanks to EURO 2012, by PLN 5.0 billion $^{8}$ (in constant 2008 prices), with the highest annual increase occurring in 2012 as a result of the inflow of foreign tourists and fans to the cities hosting the event. Under the pessimistic scenario, additional inbound tourism revenues, between 2012 and 2020, will amount to PLN 1.1 billion, i.e., 22.2\% of the revenues projected in the basic variant. Under the optimistic scenario, the additional inbound tourism revenues, 
between 2012 and 2020, will total PLN 6.0 billion, which is $121.1 \%$ of the value forecasted in the basic variant. The latter scenario projects the same number of foreign fans visiting Poland in June 2012 as the basic one.

\subsection{Infrastructure investment}

The assumptions concerning investment are based on the timetable drawn up by PL.2012 Ltd and on predicted costs of the infrastructural and organisational projects connected with the preparations for the EURO 2012 (Masterplan). A significant impact on the final shape of the scenarios is produced by the opinions of independent experts and national coordinators (PL.2012 employees) within the scope of transport, sports infrastructure and the hotel industry. The Masterplan (version as of December 2009) consists of 844 activities worth nearly 106 billion PLN, bundled into 413 projects linked with the planning of the EURO 2012. The EURO 2012 scenarios are based on the following assumptions:

- basic scenario: most of the Masterplan projects (77.4\% in value terms) are completed by mid-2012

- pessimistic scenario: some of the basic scenario investments will not be completed by mid-2012

- optimistic scenario: all the investments envisaged in the Masterplan will be completed by mid-2012.

According to the basic scenario PLN 81.3 billion will be spent on investments by mid-2012, instead of 2015 or 2020 (depending on the type of investment - see Figures 3 and 4). Figure 2 shows the composition of this amount. It can be seen from the figure that investments in transport infrastructure produce the largest impact on the Polish economy - the pertinent share amounts to $86 \%$, and $58 \%$ in case of road transport.

Figure 2 Composition of investment outlays related to EFC 2012 according to the Masterplan

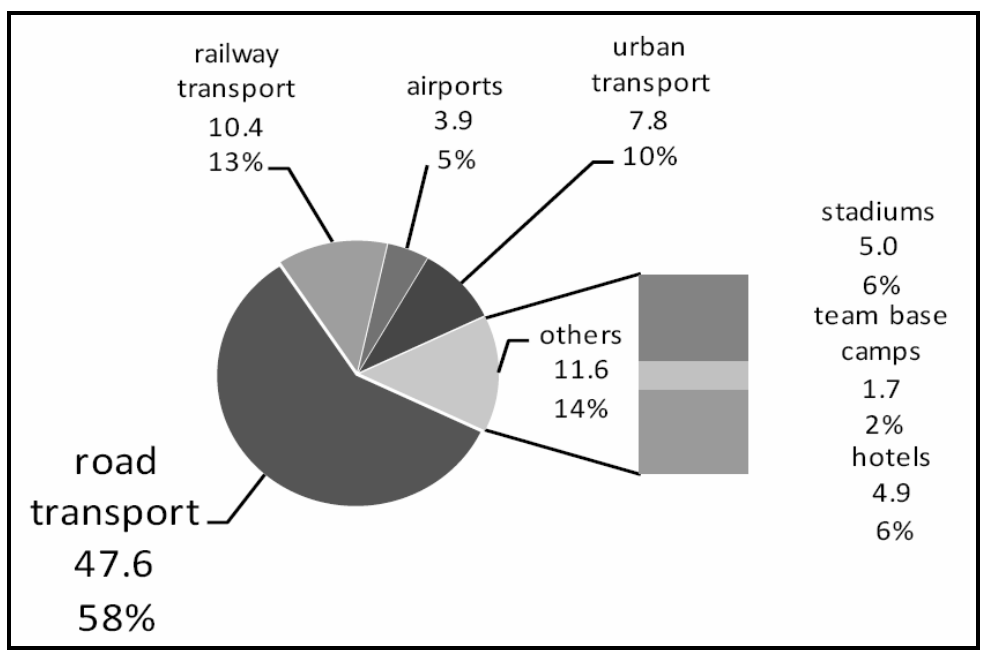

Note: Basic scenario, in PLN billion, 2009 constant prices.

Source: Authors' calculations 
Figure 3 Scenarios for investment in the transport infrastructure

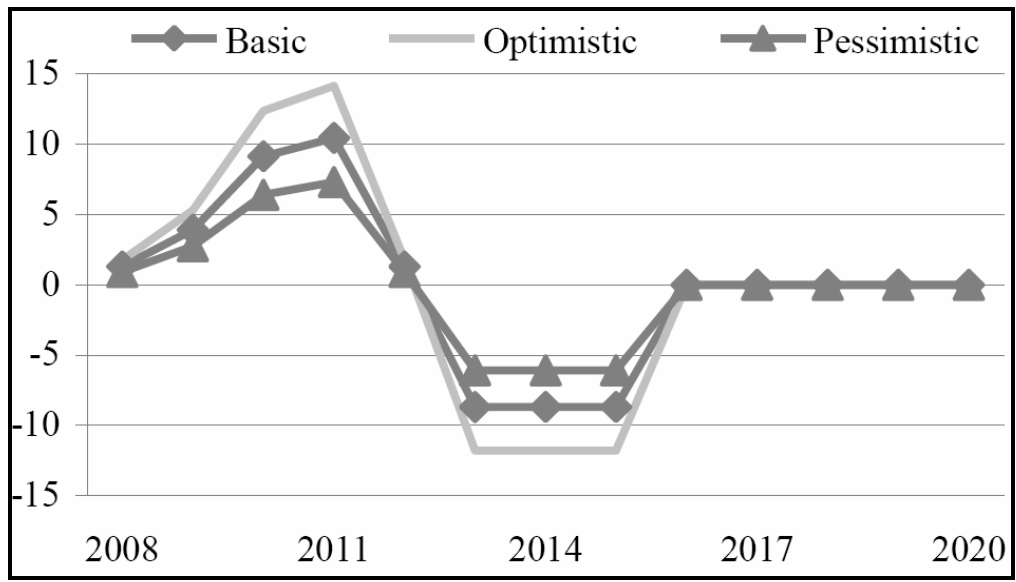

Note: bn PLN, deviations from benchmark scenario.

Source: Authors' calculations

Figure 4 Scenarios for investment in team base camps (TBC) and stadiums

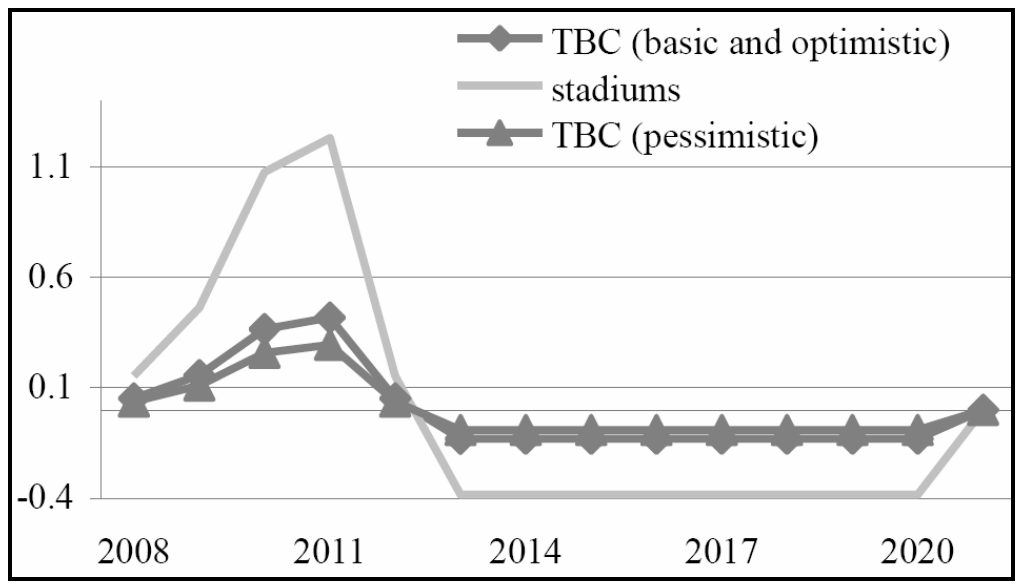

Note: bn PLN, deviations from benchmark scenario.

Source: Authors' calculations

The outlays related to the EURO 2012 have been qualified as investments in the relevant economic sectors, broken down into: transport, sports and recreation and hotels and restaurants. Table 2 provides the aggregate data for the three scenarios. 
Table 2 Scenarios for sectoral breakdown of investment outlays (2009 constant prices)

\begin{tabular}{lccc}
\hline \multirow{2}{*}{ Sector } & \multicolumn{3}{c}{ Scenario (mln PLN) } \\
\cline { 2 - 4 } & Basic & Pessimistic & Optimistic \\
\hline Transport & $69,632.2$ & $48,742.5$ & $94,348.7$ \\
$\begin{array}{l}\text { Arts, entertainment } \\
\text { and recreation }\end{array}$ & $5,007.1$ & $5,007.1$ & $5,007.1$ \\
$\begin{array}{l}\text { Accommodation and } \\
\text { catering services }\end{array}$ & $6,633.0$ & $4,643.1$ & $6,633.0$ \\
Total & $81,272.3$ & $58,392.7$ & $105,988.8$ \\
$\%$ of basic scenario & $100.0 \%$ & $71.8 \%$ & $130.4 \%$ \\
\hline
\end{tabular}

Source: Authors' calculations

The table also contains relevant data for two other scenarios derived through the modification of the basic scenario. The optimistic scenario assumes that all Masterplan Projects are implemented. Under the pessimistic scenario, the total outlays in transport, hotels, and restaurants will be $30 \%$ lower compared to the level projected in the basic scenario, while sports and recreation investments will be fully implemented (due to their strong link to the EURO 2012).

The three EURO 2012 scenarios assume that funds will be spent earlier than in the benchmark scenario. The acceleration in spending concerns mainly investments in transport infrastructure that were expected to be carried out with the EU co-financing, between 2008 and 2015 (see Figure 3). Even though the construction of motorways and expressways is not a necessary condition for hosting the tournament, it is deemed by the experts (at least in regard to some communication routes) as a related investment category. Undoubtedly, the prospect of holding the EURO 2012 in Poland speeded up the legislative, organisational, and investment activities in the field of building motorways and expressways. Hence, the pace of investment is higher compared to the benchmark scenario in 2008-2012, and lower between 2013 and 2015.

Similar assumptions have been adopted for other investments (stadiums and team base camps), the difference being that the benchmark scenario predicts they would be completed by 2020 . In the case of both team base camps and hotels, there is no difference between the basic and the optimistic scenario, and in the case of stadiums, only the basic scenario was considered (see Figure 4).

\subsection{TFP}

Total factor productivity is an important determinant of the scale of economic effects stemming from the EURO 2012 organisation in Poland. The TFP growth is driven by various factors, including the quality of transport infrastructure. The influence of the road infrastructure on TFP in the Polish economy was estimated using an econometric approach. The resulting estimates supplemented by the Masterplan data on the completion of motorways and expressways (connected with the tournament organisation) were next used to calculate the TFP level in the benchmark scenario and in the EURO 2012 scenarios. The results of the calculations, used as inputs to the ensuing simulations, are presented in Figure 5. The respective lines show percentage changes in the TFP level under the three EURO 2012 scenarios relative to the benchmark scenario. Thanks to the 
acceleration in the transport infrastructure investment, the achievable TFP level is realised sooner. This concerns only the 2010-2014 period, and starting from 2015 TFP returns to its benchmark path. The maximum deviation from the latter occurs in 2012 (nearly $0.45 \%$ for the optimistic scenario).

Figure 5 Changes in the TFP level

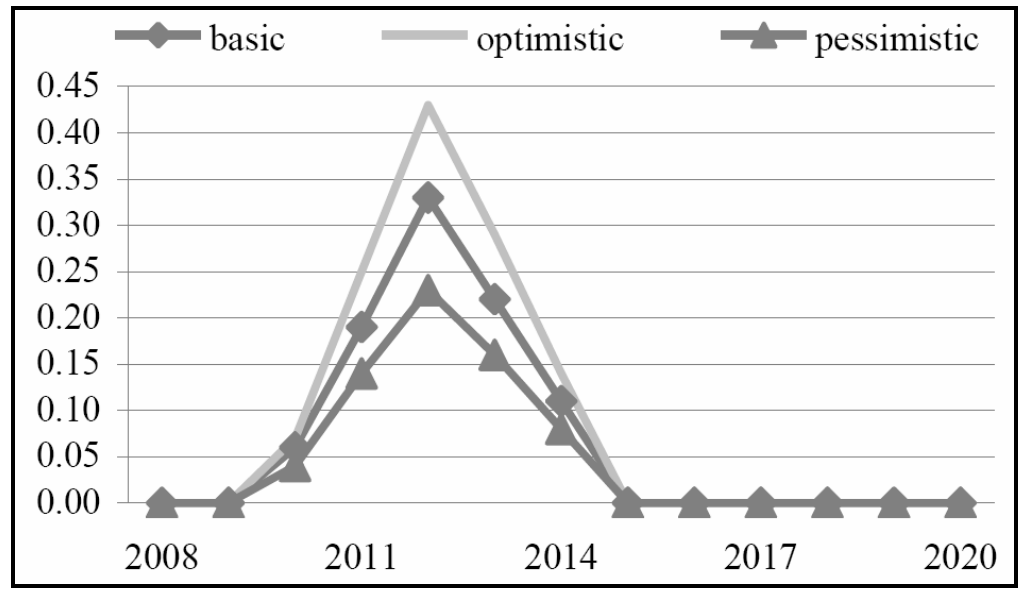

Note: \% of benchmark scenario.

Source: Authors' calculations

\subsection{FDI}

As mentioned earlier, the development of infrastructure is one of the key factors affecting the inflow of FDI. The low quality of the Polish infrastructure (and in particular, transport infrastructure) ranks among the main barriers deterring the FDI inflow (Wyżnikiewicz, 2007). The acceleration of investment outlays in transport triggered by organising the EURO 2012 should, therefore, encourage an increased FDI inflow to Poland. However, the extent to which foreign investors are attracted by improvements in the road network in Poland cannot be specified within the CGE model as it describes only the domestic economy. Therefore, we used the results provided by Bellak et al. (2009) who estimated the impact of transport infrastructure (measured by the density of transport network and the number of sea and river ports) on FDI flows to the Central and Eastern Europe (CEE) region. We used capital endowment in the transport sector as a proxy for the original infrastructure measure, and the elasticity $(0.323)$ obtained by the authors referred to above, with a one year lag.

In all three EURO 2012 scenarios the FDI are shifted in time compared to the benchmark scenario thanks to an accelerated pace of building expressways and motorways. The original FDI elasticity is applied to determine the path of FDI changes in the basic scenario. The optimistic and pessimistic variants are derived as a result of changing (raising and decreasing) the FDI elasticity by $1 / 3$ of its original value. The impact of infrastructure investment on FDI is the strongest in 2013 (1.4\% in the basic scenario compared to the benchmark). Between 2014 and 2017, the FDI time-lead effects 
will fade out, i.e., Poland will return to the path of investments and capital stock behaviour as projected under the benchmark scenario.

The effect of transport infrastructure on FDI until 2020 are shown in Figure 6.

Figure 6 Scenarios for FDI (benchmark scenario $=1$ )

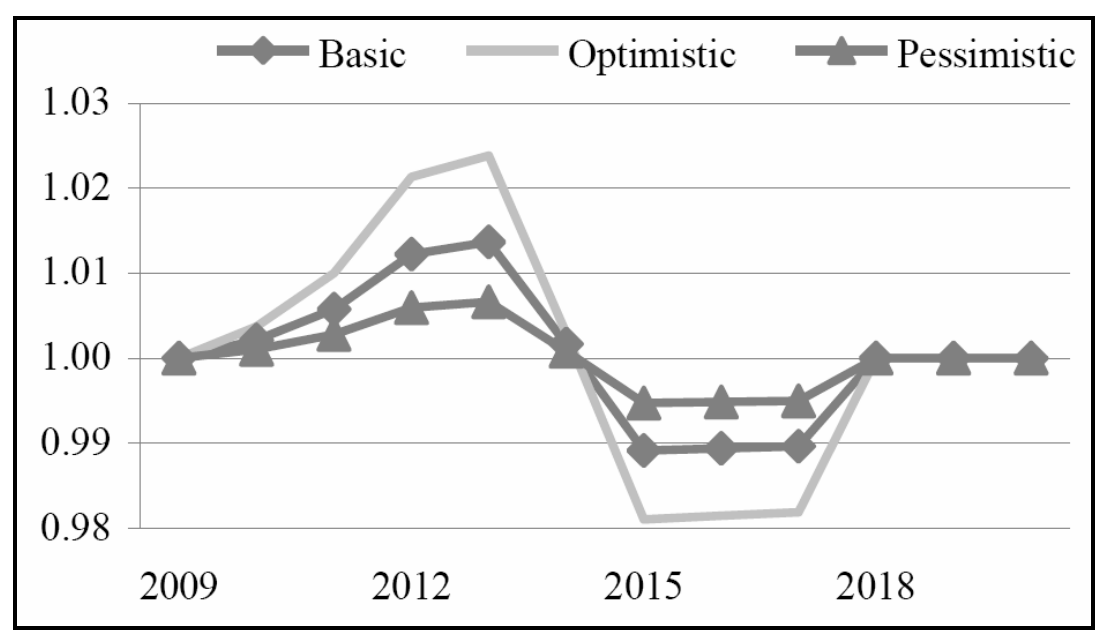

Note: Benchmark scenario $=1$.

Source: Authors' calculations

\section{Impact on the Polish economy}

\subsection{Macroeconomic impact of the EURO 2012 in Poland}

The supply-side effects are the best starting point for an explanation of our results. Figure 7 shows, in a stylised way, the idea behind the simulations presented in this paper.

Figure 7 Investment acceleration impact on economy's capacity

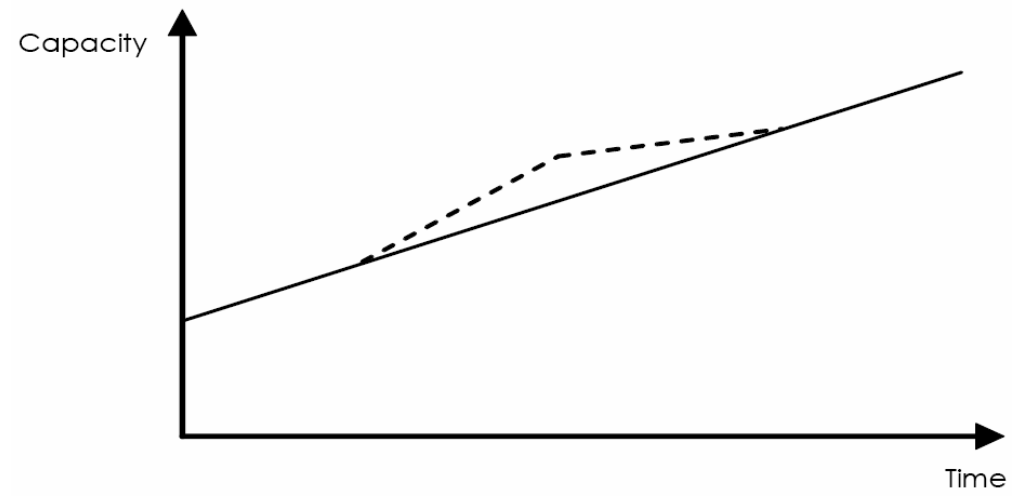

Source: Authors' design 
Infrastructure investment acceleration leads to a more rapid development of the economy's capacity in the EURO 2012 scenario (dashed-line), compared to the base (no tournament) scenario (solid line). The gain in GDP is proportional to the triangular area between the two lines (note that in the long-run the two paths of capacity changes converge). We assume that the increased capacity will be effectively absorbed by changes on the demand side, so that the GDP level temporarily rises (or, in other words, there is a cumulative increase in GDP).

Balancing of commodity markets after capacity changes is facilitated by price adjustments, which invoke substitution effects (e.g., changes in the structure of household demand and changes in the import intensity of demand). The model also shows how altered economic conditions cause labour reallocation among industries, driven by the cost minimising behaviour of producers. As a result we observe adjustments in practically all economic variables, making it rather difficult to track all the interdependencies.

According to the simulation results, the EURO 2012 preparations will result in accelerated economic growth between 2008 and 2012 (see Figure 8). In the subsequent years (2013-2016), the growth rate will be lower, compared to the benchmark scenario, and eventually it will get back to its long-run path. The maximum acceleration of GDP growth - under the basic scenario - amounts to almost $0.2 \mathrm{pp}(0.25 \mathrm{pp}$ in the optimistic variant, and just below $0.14 \mathrm{pp}$ in the pessimistic one). The increased GDP growth rate translates into a temporary rise in its absolute level (see Figure 9), especially in 2011-2014. The peak year is 2012, with a positive deviation amounting to PLN 5.4-9.5 billion (constant 2009 prices) - depending on the scenario.

Figure 8 GDP growth rate - deviations from the benchmark scenario (in p.p.)

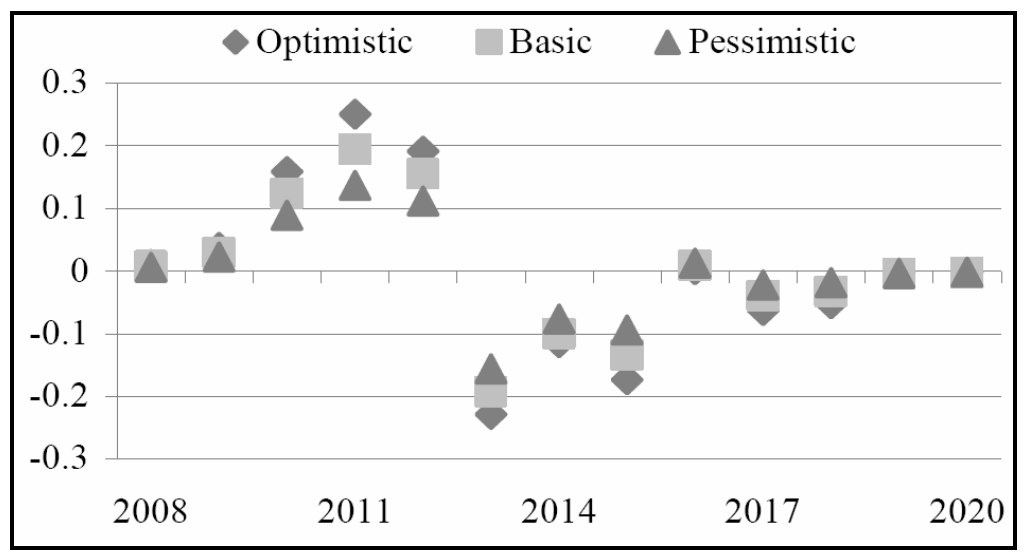

Source: Authors' calculations 
Figure 9 GDP - deviations from the benchmark scenario (PLN billion, constant 2009 prices)

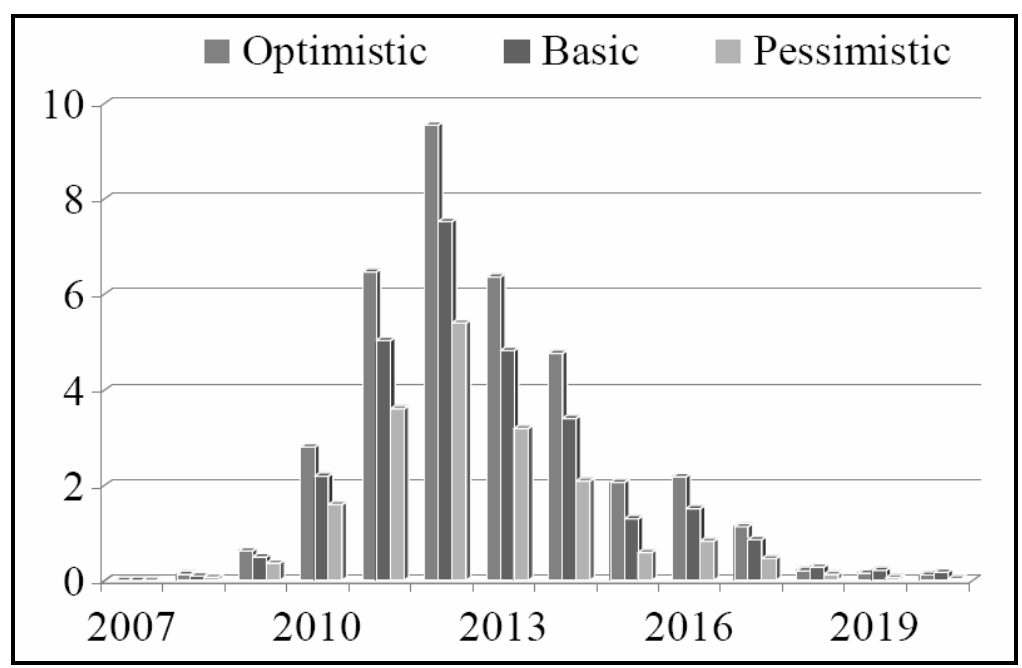

Source: Authors' calculations

The cumulative effects of the EURO 2012 are presented in Table 3. These are sums of annual increments in selected macroeconomic variables between 2008 and 2020. Seen from this angle, the benefits stemming from the organisation of the tournament, in terms of incremental GDP, add up to PLN 27.9 billion ${ }^{9}$ (2009 constant prices) in the basic scenario. This is equivalent to $2.1 \%$ of the 2009 GDP level. Under the pessimistic variant, that effect totals $1.4 \%$, while under the optimistic scenario it amounts to $2.7 \%$.

Table 3 Cumulative effects of EURO 2012

\begin{tabular}{lccc}
\hline \multirow{2}{*}{ Category } & \multicolumn{3}{c}{ Scenario $($ bn PLN) } \\
\cline { 2 - 4 } & Basic & Pessimistic & Optimistic \\
\hline GDP & 27.9 & 18.4 & 36.6 \\
Consumption & 20.5 & 12.8 & 26.7 \\
Investment & 2.7 & 1.8 & 3.8 \\
Exports & 21.9 & 14.2 & 28.7 \\
Imports & 17.2 & 10.3 & 22.6 \\
Tax revenues & 5.9 & 4.1 & 7.7 \\
\hline
\end{tabular}

Note: Total increase in 2008-2020, in constant 2009 prices.

Source: Authors' calculations

The incremental GDP is predominantly absorbed by additional household consumption (augmenting by PLN 12.8-26.7 billion) and exports (growing by PLN 14.2-28.8 billion). Changes in aggregate household consumption are proportional to changes in disposable income [equation (10)], which, in turn, roughly follow the GDP variation. The productivity induced export expansion does not deteriorate the terms of trade (see Section 3). Imports grow in par with exports, albeit a bit more slowly - by PLN 10.3-22.6 billion (2009 prices). This is the immediate result of the domestic demand increase [see equation (6) as an example]. The government consumption - in line with the simulation assumptions - does not deviate from the benchmark scenario. However, 
EURO 2012 gives also rise to higher, cumulative (real) tax revenues. Their incremental value, during the examined period, amounts to PLN 4.1-7.7 billion, depending on the scenario.

The simulation results show a slight cumulative growth in investment. Most of the investment deviations over the examined period cancel out, as the initial increase (or time-lead) of investment outlays in public infrastructure and stadiums is later offset by their decrease (the same pattern applies to FDI). The positive overall effect of gross fixed capital formation (PLN 2.7 billion in the basic scenario) results solely from the endogenous responses of private investment to altered economic conditions. According to equation (14), private investment is stimulated whenever there is an increase in the ratio of expected capital rentals to the cost of constructing new capital. Private investment responses varied between sectors and in time. In general, however, a (rather moderate) crowding out effect was observed - in the years of intensified public investment, private investment was lower compared to the no-event (benchmark) scenario, and vice versa. This is because increased public investment in the preparation period push up their cost, while there is an opposite effect when public investment are slowed down after the preparations are completed. The relatively small magnitude of cumulative private investment increase can be explained by the fact that the EURO-induced shocks we have modelled are only transitory, whereas investment decisions are based on the maximisation of long-term return. In other words, there is no (or very little - related to permanent boost of foreign tourists' expenditure) stimulus to permanently expand private capital stocks. Thus, explanation of the (modest) capital expansion is that overall, the productivity increase transiently makes creation of new capital less costly.

The organisation of the EURO 2012 is also projected to foster employment (Figure 10). In the peak year 2012, the expected additional employment, compared to the benchmark scenario, comes to 20-33 thousand full-time equivalent jobs, depending on the simulation variant (these estimates do not include the self employed). On average, the deviation from the benchmark scenario is equal to 8.2 thousand employees per year.

Figure 10 Employment - deviations from the benchmark scenario

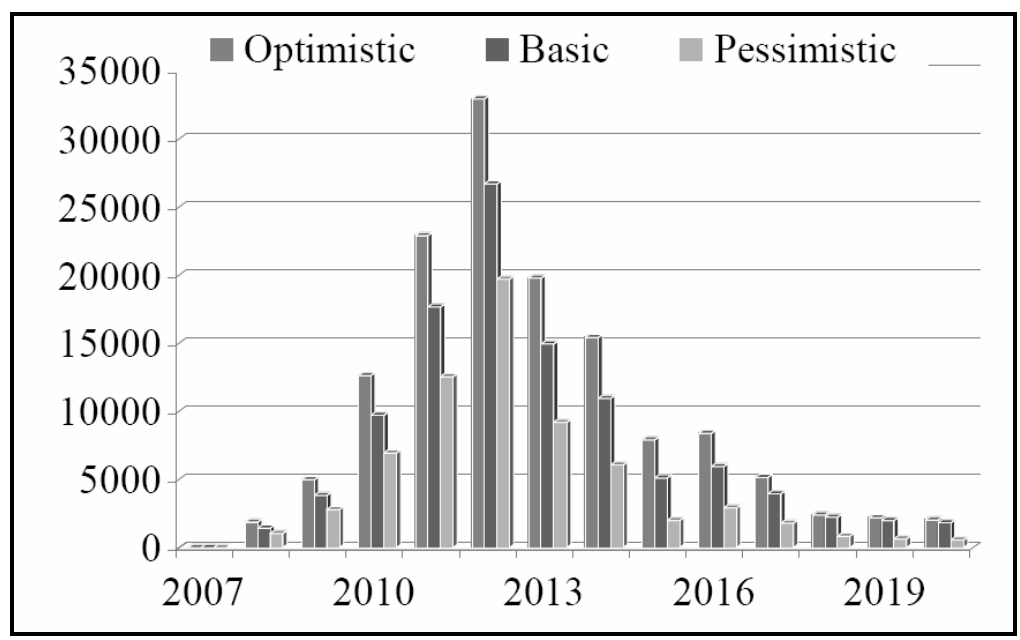

Source: Authors' calculations 
In CGE model simulations often one of the two extreme alternatives concerning labour market closure is adopted - fixed aggregate labour supply (typically in long-run simulations) or perfectly elastic labour supply (typically in short-run simulations). The set-up of labour market behaviour may have a significant impact on the results (see Madden, 2006). By implementing a simple labour supply mechanism, we take an intermediate position between the two mentioned alternatives, i.e., we allow aggregate employment to increase, but at the cost of higher wages. Although the simulation horizon is relatively long, this approach seems justified by the fact that the analysed shocks are mostly transitory. Further, the global financial crisis of 2008-2009 and the concomitant slack in the labour market suggest that responsiveness of employment to a positive shock should be relatively high. On the other hand, we avoid overoptimistic estimates of the EURO 2012 impact, likely to arise under the assumption of perfectly elastic labour supply.

\subsection{Impact per sources}

Out of all impact channels being scrutinised in the study, this is the acceleration of transport infrastructure development that turns out to be the most important source of the EURO-related effects in the Polish economy. As can be seen in Figure 11,77.5\% of total incremental GDP growth in 2008-2020 may be attributed to this source. It may be claimed that the pertinent share is even higher (by $7.8 \mathrm{pp}$ ) if we add the FDI effects which are actually also driven by a more dynamic development of transport infrastructure. The construction of stadiums and team base camps ahead of time contributes $6.4 \%$ of the incremental GDP growth while the foreign tourist expenditure $-7.3 \%$ of the total. Finally, the UEFA budget expenditures explain $1 \%$ of the cumulative GDP increase.

Figure 11 Sources of the cumulative GDP increase in the basic scenario

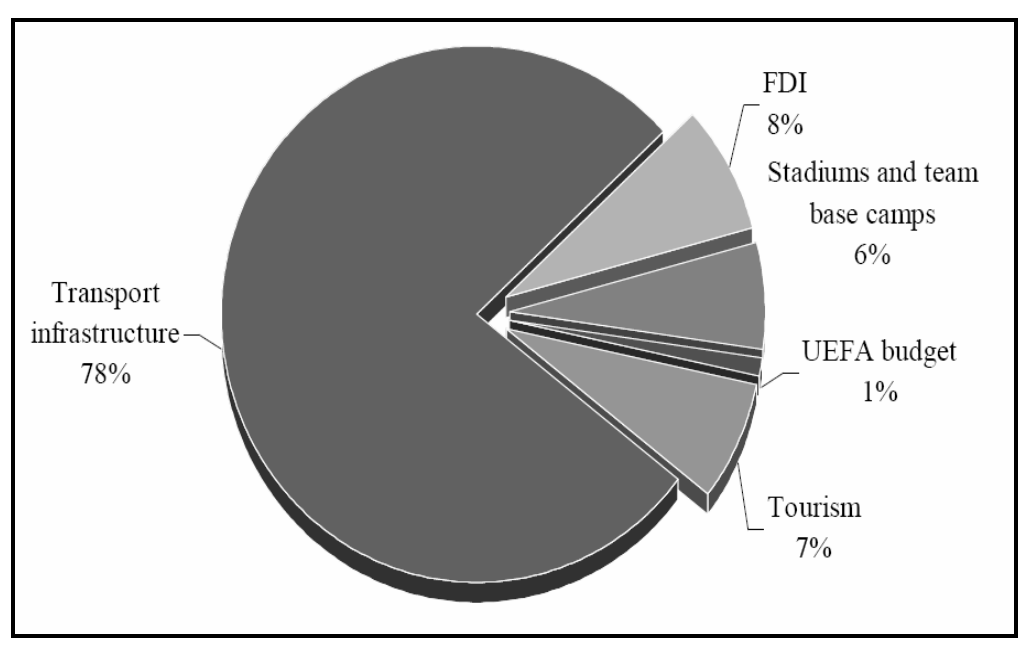

Source: Authors' calculations

The gains from the development of transport infrastructure may be interpreted as a supply-side effect, having two components. The first component is a temporary additional TFP growth [imposed by exogenous shocks to TFP in equation (3)], compared 
to the benchmark scenario, due to the acceleration in building expressways and motorways. The second component consists of the rise of fixed capital stock (between 2009 and 2015) as a consequence of the advanced completion of investment projects in airport, railway and urban transport infrastructure [this is facilitated by exogenous shocks to public investment in the transport sector - see equation (13)]. The culmination of the GDP incremental growth in 2012 implies that in this particular year the economic potential (capital stock and TFP) displays the largest positive deviation from its hypothetical level under the benchmark scenario. The demand shocks - that also happen to be the strongest in 2012 - compound to a certain extent this effect but without playing a major role.

The modelling of the FDI impact on the Polish economy was based on exogenous increments in the fixed capital formation in respective industries alone (the specific industry composition of FDI inflows in Poland was taken into account), which induced larger capital stocks. On the other hand, the simulation does not assume any extra productivity gains, often attributed to FDI. Hence, the projected FDI effects should be deemed conservative and being at the lower bound of possible benefits.

Forcing the pace of building stadiums and team base camps constitutes - similar to the pattern revealed in transport infrastructure - a positive supply shock. The capacity achieved ahead of time, compared to the benchmark scenario, generates an additional flow of services, thus triggering accelerated GDP growth. The assumptions on expected revenues and profitability of investment projects in sport-related infrastructure, as well as the impact of these projects on the remaining parts of the pertinent sectors (hotels in case of the team base camps and recreation and sports industry in case of the stadiums) were based on expert opinions in relevant fields. With a view to making the simulation results consistent with expert forecasts, it was necessary to assume certain exogenous changes in the structure of household consumption (taste shifts) and exports [by appropriate adjustment of parameters of equations (9) and (11)]. The UEFA budget effect should be interpreted in terms of a one-off demand shock. All the above-mentioned factors contribute to a cumulative GDP increment during the whole analysed period amounting to approx. PLN 1.6-1.9 billion, in 2009 prices.

The increased inbound tourism revenues translate into a cumulative GDP rise between 2012 and 2020, in the amount of PLN 1.9 billion (2009 constant prices) - according to the basic scenario. In the optimistic scenario, this effect totals PLN 2.3 billion, while in the pessimistic one, it slightly exceeds PLN 0.4 billion. This implies that the cumulative GDP growth due to the increase in foreign tourist arrivals is roughly half the size of additional inbound tourism revenues. This result may be explained by the existing supply constraints and substitution effects - the increased tourists' expenditures may create more jobs in tourist services sector, partly at the expense of employment in other industries. Moreover, the new tourist demand indirectly boosts imports, as it causes a slight appreciation of the domestic currency (real exchange rate is allowed to adjust in this case), and by the same token constrains growth of the domestic output.

The economic shock generated by the organisation of the EURO 2012 exerts a differentiated influence on individual sectors of the Polish economy. Due to the very nature of the shock, which stems mainly from the advanced timing of investment outlays, the largest changes occur in the construction industry (see Figure 12). The projected construction output augments between 2008 and 2012 in comparison with the benchmark scenario. The most sizeable increase - ranging from $2.2 \%$ up to $4.4 \%$ - takes place in 
2010-2011, depending on the simulation scenario. In the 2013-2015 period, the output involved decreases by $1.5 \%-2.8 \%$ as a result of a slow down in infrastructure investment. It is worth noting that the negative deviations from the benchmark scenario would be even deeper, were it not for some induced growth of private investment subsequent to the preparations for the EURO 2012.

Figure 12 Construction output - percentage deviations from the benchmark scenario

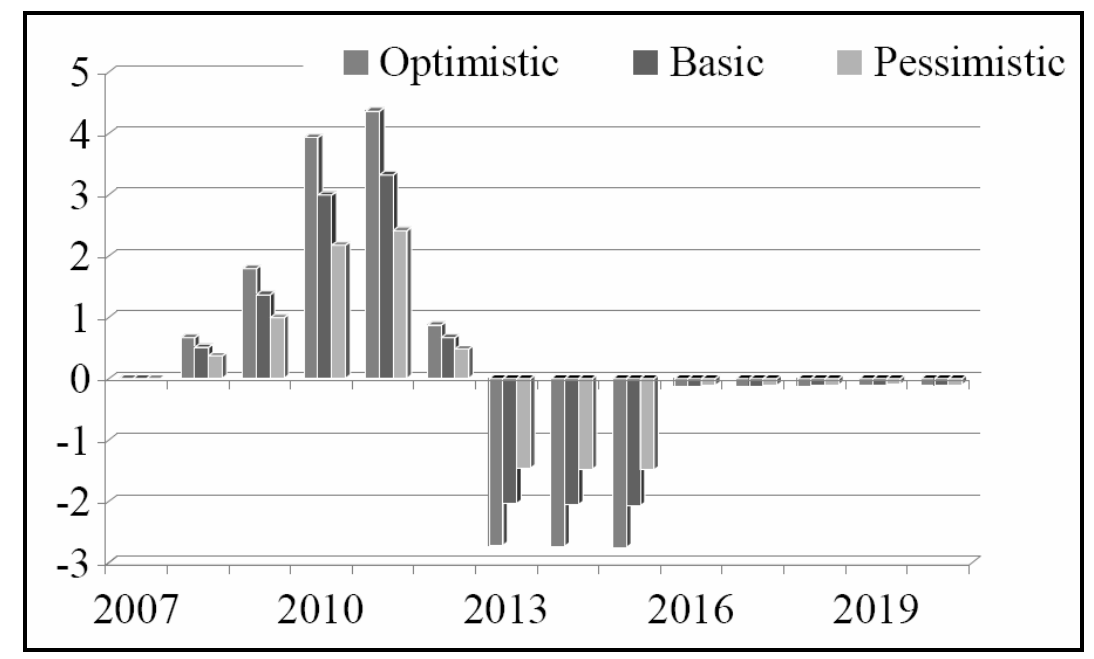

Source: Authors' calculations

\subsection{Comparison of simulation results with those for other countries}

The direct reference for our findings regarding the projected impact of the organisation of the EURO 2012 on the Polish economy are the estimated effects of two previous EFC, organised in Austria and Switzerland (2008), and in Portugal (2004). In order to ensure comparability of the results for Poland, the economic effects of the EFC held in other countries have been transformed in such a way that the cumulative GDP growth figures (in constant prices) are expressed as percentages of the annual GDP level three years before the event. Sticking to this format of data presentation, in a study on the EFC in Portugal (Martins et al., 2004), the real GDP gains were estimated at $0.56 \%$. According to the same estimates, employment augmented by approx. 39.4 thousand 'man-years' (measured as full-time equivalent jobs). In turn, the approximate EFC 2008 impact on the Swiss economy (Rütter et al., 2004), in terms of incremental GDP, amounted to $0.06 \%-0.07 \%$, depending on the simulation variant. Simultaneously, the Championship generated 3.2-3.8 thousand new jobs. The authors argued, however, that only a part of the job-creation effect will materialise as actual new jobs, the remaining part being a derivative of employment inflows from other activities. In Austria, the estimated cumulative GDP increase came to $0.25 \%$, while the incremental employment was 11.8 thousand full-time equivalent annual jobs (Helmenstein and Kleissner, 2008). The key economic effects of the EFC in the countries involved are shown in Table 4. As for Switzerland, only the outcomes reported in the optimistic scenario were taken into consideration. 
Table 4 The economic effects of UEFA EFC in Portugal, Austria, Switzerland, and Poland

\begin{tabular}{lccc}
\hline Country & Impact horizon & $\begin{array}{c}\text { Total GDP } \\
\text { increase (in } \%)^{1}\end{array}$ & $\begin{array}{c}\text { Incremental employment } \\
\text { (in thousands of full-time annual jobs) })^{2}\end{array}$ \\
\hline Portugal & $\begin{array}{c}\text { 3 years } \\
\text { Austria }\end{array}$ & 0.56 & 39.4 \\
Medium-term ${ }^{3}$ & 0.28 & 11.8 \\
Switzerland & Medium-term ${ }^{3}$ & 0.07 & 3.8 \\
Poland & 13 years & 2.09 & 106.3 \\
\hline Notes: ${ }^{1}$ Cumulative GDP increase, in constant prices, compared to the annual GDP level \\
three years prior to the EFC. For Portugal, Austria and Switzerland, the entries \\
represent increase in value added. Due to about the same dynamics of both \\
variables, the rise in value added may be identified with the GDP increases. \\
${ }^{2}$ In the case of Switzerland the result is a rough approximation (job duration was \\
not reported); the effect is the number of full-time jobs generated by the EFC, \\
which does not translate into a change in aggregate employment. As for Poland, \\
the result refers only to people employed under the legal labour contracts \\
(i.e., they exclude the self-employed). \\
${ }^{3}$ Medium-term period = a few years. The authors do not specify the time span \\
within which the economic effects of EFC materialise. \\
Source: $\quad$ Authors' calculations
\end{tabular}

Against this background, the projected economic effects of the EURO 2012 for the Polish economy are relatively large. However, the preparations to this sporting event in Poland constitute a much larger-scale undertaking than in the countries hosting the EFC in the past, which is mainly due to the pervasive shortages in transport and stadium infrastructure, and the generally lower level of economic development. In Switzerland, the only EFC-related investment outlay was the extension of the stadium in Basel (CHF 23 million). A similar pattern held in Austria where all pertinent investments (EUR 72.4 million) were confined to stadium infrastructure only. In turn in Portugal, the total investment outlays, spread over three years, amounted to less than EUR 1 billion. Most of them were earmarked for building the stadiums, while some funds were also spent on access road construction. These amounts are considerably lower than the scale of the EFC-related investments in Poland, even if one allows solely for the amounts 'shifted' from the future rather than their total magnitude.

In Poland, most of the EFC-related investments are earmarked for those areas of infrastructure that are decisive for the economy's efficiency, such as the network of motorways and expressways covering a large part of the country. Hence, the main economic benefits derived from the organisation of the EURO 2012 are due to the advanced timing (or time-lead) of investment and earlier arrival at higher economic potential (capacity), which in turn translates into higher GDP and consumption levels. In contrast, the nature and scale of investments in other host countries did not entail any significant gains in terms of higher capacity. This is why this channel of EFC impact on the economy was neglected in the abovementioned studies, whose authors focused instead on demand shocks. Bearing in mind their nature, the economic impulses related to the organisation of the EURO 2012 in Poland are also more persistent (extending over a longer period) than in the case of the reference countries.

Unlike in this study, the reports on economic outcomes of the EFC in Portugal, Austria, and Switzerland pay no heed to the discussion of the 'Barcelona effect'. Still, it 
is quite justifiable as tourism in these countries is well established and their tourist attractiveness was relatively high already before the event.

The evaluation method applied in our study (based on the CGE model) differs from the approach adopted in the reports referred to earlier (input-output methods). The estimates of economic benefits stemming from mega sporting events, based on the CGE models, are believed to be more conservative than those embedded in a typical input-output framework.

\section{Conclusions}

The purpose of this paper was to assess the impact of the organisation of the EURO 2012 on the Polish economy during the 2008-2020 time period. The tool used for the simulation of the EURO 2012-induced effects was the dynamic CGE model describing the economy in a 41-industry breakdown.

The main source of the EURO-induced economic effects is the time-lead of investments in transport infrastructure (roads, railways, urban transportation, airports), as well as in stadiums, and team base camps. The analogous acceleration scenario applies to FDI, whose increased, earlier inflow is encouraged thanks to improved transport infrastructure. Still another EURO-related economic impulse comes from the increased number of foreign tourists arriving to Poland in 2012 and in the subsequent years. The estimated UEFA operational budget expenditures give birth to a separate demand shock in 2012 .

As a direct consequence of the advanced timing of investments, the Polish economy is expected to attain its higher potential sooner, modelled mostly as a rise in TFP. This effect is conducive to a projected additional $1.4 \%-2.7 \%$ GDP increase, compared to its 2009 level. The total cumulative GDP increase is spread unevenly over the period of 2008-2020 with the peak occurring in 2012. The maximum increment in employment takes place in 2012, amounting to 20-33 thousand full-time annual jobs. The average annual employment increase totals 8.2 thousand persons (including paid employees only).

The most important single source of EURO 2012-induced economic gains in Poland is the acceleration of transport infrastructure investments, which contributes $77.5 \%$ to the cumulative GDP increase (basic scenario). The other major sources include the advanced timing in FDI inflow, increased tourist consumption, and utilisation of stadiums and team base camps.

The benefits that accrue from hosting the UEFA EURO 2012 herein, are by far more sizeable than those experienced in the reference host countries. While the estimated, cumulative GDP increase in Poland amounts to $2.1 \%$ of its 2009 level, the pertinent figure for Portugal (EFC 2004) was 0.56\%, and those for Austria and Switzerland (EFC 2008) $-0.28 \%$ and $0.06 \%-0.07 \%$, respectively. In contrast to the patterns established in the other host countries, the most significant economic gains from the organisation of the EURO 2012 in Poland are derived from the supply-side, and in particular - from positive supply shocks driven by the advanced timing of investments in transport infrastructure. Moreover, the impact of expanded economic potential extends over a longer period than the effects generated by the demand shocks examined in the reference countries. 


\section{Acknowledgements}

This paper draws on economic modelling commissioned by PL.2012 Ltd, a special purpose vehicle of the Minister of Sport and Tourism in Poland. PL.2012 is the coordinator and overseer of preparation undertakings for EURO 2012 in Poland. The Authors would like to thank the two anonymous referees for their constructive comments and suggestions.

\section{References}

Ahlert, G. (2005) 'What does Germany expect to gain from hosting the 2006 Football World Cup - macroeconomic and regional economic effects', GWS (Gesellschaft für Wirtschaftliche Strukturforschung) Discussion Paper 2005/4 [online] http://www.gwsos.com/discussionpapers/gws-paper05-4.pdf (accessed 06 January 2013).

Almon, C. (1991) 'The INFORUM approach to interindustry modeling', Economic Systems Research, Vol. 3, No. 1, pp.1-7.

Almon, C. (1996) 'A perhaps adequate demand system', Inforum Working Paper No. 96-007 [online] http://inforumweb.umd.edu/papers/wp/wp/1996/wp96007.pdf (accessed 31 December 2012).

Bellak, C., Leibrecht, M. and Damijan, J.P. (2009) 'Infrastructure endowment and corporate income taxes as determinants of foreign direct investment in Central and Eastern European countries', The World Economy, Vol. 32, No. 2, pp.267-290.

Blake, A. (2005) 'The economic impact of the London 2012 Olympics', Christel DeHaan Tourism and Travel Research Institute, Nottingham University DISCUSSION paper No. 5 [online] http://epress.lib.uts.edu.au/research/bitstream/handle/10453/19780/Impact\%202005_5.pdf?seq uence $=1$ (accessed 06 January 2013).

Bohlmann, H.R. and van Heerden, J.H. (2008) 'Predicting the economic impact of the 2010 FIFA World Cup on South Africa', International Journal of Sport Management and Marketing, Vol. 3, No. 4, pp.383-396.

Boratyński, J. (2009) Analiza tworzenia $i$ podziatu dochodów na podstawie modelu wielosektorowego, Wydawnictwo Uniwersytetu Łódzkiego, Łódź.

Borensztein, E., De Gregorio, J. and Lee, J-W. (1998) 'How does foreign direct investment affect economic growth?', Journal of International Economics, Vol. 45, No. 1, pp.115-135.

Bougheas, S., Demetriades, P.O. and Morgenroth, E.L.W. (1999) 'Infrastructure, transport, cost and trade', Journal of International Economics, Vol. 47, No. 1, pp.169-189.

Brealey, R.B. and Myers, S.C. (2000) Principles of Corporate Finance, Irwin/McGraw-Hill, London.

Brunet, F. (2005) 'The economic impact of the Barcelona Olympic Games, 1986-2004: Barcelona: the legacy of the Games, 1992-2002', Barcelona Centre d'Estudis Olímpics UAB Issue: 2005, pp.1-27 [online] http://olympicstudies.uab.es/pdf/wp084_eng.pdf (accessed 3 July 2009).

Button, K. (1996) 'Infrastructure investment, endogenous growth and economic convergence', The Annals of Regional Science, Vol. 32, No. 1, pp.145-162.

Chatterjee, S, Sakoulis, G. and Turnovsky, S.J. (2003) 'Unilateral capital transfers, public investment, and economic growth', European Economic Review, Vol. 47, No. 6, pp.1077-1103.

Choe, J.I. (2003) 'Do foreign direct investment and gross domestic investment promote economic growth?', Review of Development Economics, Vol. 7, No. 1, pp.44-57.

Démurger, S. (2001) 'Infrastructure development and economic growth: an explanation for regional disparities in China?', Journal of Comparative Economics, Vol. 29, No. 1, pp.95-117. 
Dixon, P.B. and Parmenter, B.R. (1996) 'Computable general equilibrium modelling for policy analysis and forecasting', in Amman, H.M., Kendrick, D.A. and Rust, J. (Eds.): Handbook of Computational Economics, Vol. 1, North-Holland, Oxford.

Giesecke, J. and Madden, J. (2007) 'The Sydney Olympics, seven years on: an ex-post dynamic CGE assessment', Centre of Policy Studies, Monash University, General Paper, No. G-168 [online] http://www.monash.edu.au/policy/ftp/workpapr/g-168.pdf (accessed 06 January 2013).

Harrison, W.J. and Pearson, K.R. (1996) 'Computing solutions for large general equilibrium models using GEMPACK', Computational Economics, Vol. 9, No. 2, pp.83-127.

Helmenstein, C. and Kleissner, A. (Eds.) (2008) Volkswirtschaftliche Effekte der UEFA EFC 2008 in Österreich, SportsEconAustria, Institut für Sportökonomie, Wien.

Horridge, M. (2003) 'ORANI-G: a generic single-country computable general equilibrium model', Centre of Policy Studies, Monash University [online] http://www.monash.edu.au/policy/oranig.htm (accessed 06 January 2013).

Kasimati, E. (2003) 'Economic aspects and the Summer Olympics: a review of related research', International Journal of Tourism Research, Vol. 5, No. 6, pp.433-444.

Kasimati, E. and Dawson, P. (2009) 'Assessing the impact of the 2004 Olympic games on the Greek economy: a small macroeconometric model', Economic Modelling, Vol. 26, No. 1, pp.139-146.

Kim, H.J., Gursoy, D. and Lee, S-B. (2006) 'The impact of the 2002 World Cup on South Korea: comparisons of pre- and post-games', Tourism Management, Vol. 27, No. 1, pp.86-96.

Madden, J. (2006) 'Economic and fiscal impacts of mega sporting events: a general equilibrium assessment', Public Finance and Management, Vol. 6, No. 3, pp.346-394.

Madden, J.R. (2002) 'The economic consequences of the Sydney Olympics: the CREA/Arthur Andersen study', Current Issues in Tourism, Vol. 5, No. 1, pp.7-21.

Malakellis, M. (2000) Integrated Macro-Micro-Modelling Under Rational Expectations, with an Application to Tariff Reform in Australia, Physica-Verlag, Heidelberg.

Markusen, J.R. and Venables, A.J. (1997) 'Foreign direct investment as a catalyst for industrial development', NBER Working Paper No. 6241.

Martins, M.V. (Ed.), Tenreiro, F., Mendes, J.M.Z. and Jacinto, A. (2004) Ocena skutków ekonomicznych EFC 2004, Raport końcowy, Instytut Ekonomii i Zarządzania Politechniki Lizbońskiej, Lizbona.

Matheson, V.A. and Baade, R.A. (2004) 'Mega-Sporting events in developing nations: playing the way to prosperity?', College of the Holy Cross Working Paper No. 04-04 [online] http://college.holycross.edu/RePEc/hcx/Matheson_Prosperity.pdf (accessed 06 January 2013).

PricewaterhouseCoopers (2004) 'The economic impact of the Olympic games', European Economic Outlook, June.

Ribeiro, C.J., Viseu, J., Delalande, T. and Rodrigues, C. (2004) 'UEFA Euro 2004 tourism impact analysis', NIPE working paper 14/2004, Uniwersytet Minho [online] http://www3.eeg.uminho.pt/economia/nipe/docs/2004/NIPE_WP_14_2004.PDF (accessed 28 April 2009).

Rütter, H., Amstutz, M., Stettler, J., de Bary, A. and Grozea-Helmenstein, D. (2004) Economic Impact of the UEFA EFC 2008 ${ }^{\mathrm{TM}}$ in Switzerland, Rütter + Partner, Luzern.

Shaffer, M., Greer, A. and Mauboules, C. (2003) Olympic Costs and Benefits: A Cost-Benefit Analysis of the Proposed Vancouver 2010 Winter Olympic and Paralympic Games, Canadian Centre for Policy Alternatives - BC Office, Vancouver.

Wyżnikiewicz, B. (2007) Raport z badania satysfakcji inwestorów z ushug świadczonych przez PAIIIZ S.A [online] http://www.paiz.gov.pl/files/?id_plik=8726 (accessed 31 December 2012). 


\section{Notes}

1 While the Championship is organised by Poland and Ukraine, this study is focused exclusively on Poland.

2 The input-output models were used for example by Martins et al. (2004), Helmenstein and Kleissner (2008), Rütter et al. (2004), and the CGE models by Madden (2006), Giesecke and Madden (2007), Blake (2005) and Bohlmann and van Heerden (2008).

3 Statistical classification of economic activities in the European Community (Nomenclature statistique des activités économiques dans la Communauté européenne).

4 Classification of individual consumption by purpose.

5 In the period preceding the event the investments in team base camps are the only outlays financed by private sector. Infrastructure investments are co-financed from the EU structural and cohesion funds with the assumed share of external financing at $35 \%-40 \%$. Hence, the public sector plays a dominant role in the investment process accompanying the EURO 2012 in Poland.

6 This effect was first observed after the Olympic Games in Barcelona in 1992, where inbound tourism arrivals doubled due to this event, reaching 3.5 million people in 2000 (Brunet, 2005).

7 Anholt-GfK Roper Nation Brands Index ${ }^{\mathrm{SM}}$ in the 'Tourism' category (see http://www.gfkamerica.com/practice_areas/roper_pam/nbi_index/index.en.html).

8 For international comparison please refer to exchange rates published by the National Bank of Poland (http://www.nbp.pl). For example the yearly average USD/PLN exchange rate was equal to 2.41 in 2008 and 3.12 in 2009.

9 USD 9.0 bn according to the 2009 average USD/PLN exchange rate (see footnote 5). 